Military Technical College Kobry El-Kobbah, Cairo, Egypt

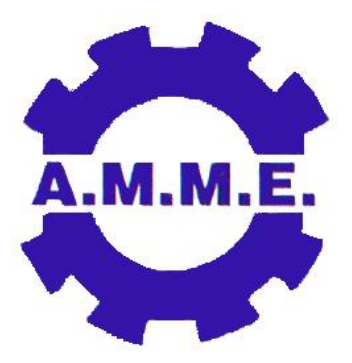

14th International Conference on Applied Mechanics and Mechanical Engineering.

\title{
Reinforced Concrete Beam Sections Under Biaxial and Axial Force: An Exact Solution
}

\section{By}

R. Hussein*

\begin{abstract}
:
This paper introduces a fundamentally clear approach to analyze and design reinforced concrete $T, L$ and rectangle beam sections under biaxial bending and axial compression or tension force. For the first time since 1844, the paper shows how a given set of design requirements can be met exactly in a unified method using closed form solution and the concept of modular programming. The new approach provides an exact solution to the mechanics equations by direct integration of the normal stresses over the concrete and steel areas. To computerize this approach, the concept of modular programming was found suitable and attractive for such application. The advantages of the new approach include rigorous calculations; resolving the disadvantages and shortcomings of the published pertinent numeric methods such as lack of accuracy, numeric instability, and nonconvergences, and meeting the needs for simple and fast computational tools for the daily design and educational practices. Also, the paper provides details of the computer formulation for the closed form solution. To demonstrate its validity and viability, eleven numeric applications are presented covering a broad spectrum of diverse problems some of which were solved manually in the literature by prominent scholars.
\end{abstract}

\section{Keywords:}

Biaxial bending, Columns, Analysis; Design; L-section, Rectangle section, Strength, Tsection, Uniaxial. 
Proceeding of the $14^{\text {th }}$ AMME Conference, 25 -27 May 2010

* Engineering Systems, Cairo, Egypt 


\section{Introduction:}

Beams represent one of the inevitable structural elements in concrete buildings. Rarely if ever, they are subjected to one load pattern from construction to demolition. They are usually subjected to biaxial bending and axial forces as a result of architectural layouts and geometry, the shape of the cross-section, or the type of exerted external loads such as seismic, wind, and the various moving loads.

In general, determining the strengths of reinforced concrete sections under biaxial bending has been the aims of many studies all of which investigated columns without demonstrations on or attention given to the boundary case of beams, except in one article (Park, 1967) since 1840. Even then, only charts were produced for the practical analysis of rectangle sections subjected bending about two axes with no axial force.

From engineering perspective, the overall analysis and design of reinforced concrete sections subjected to biaxial bending and axial force are more complex and cumbersome than sections under uniaxial bending with or without forces. As a result, there have been universally widespread interests for developing simplified methods. At present, the approximate procedures for columns include the methods of load contour, reciprocal load, the superposition, and the equivalent uniaxial eccentricity. In any of these methods, a section and a reinforcement pattern are usually assumed first, and then a prescribed trial and adjustment procedure is followed.

From computational perspective, the use of computers didn't introduce exact solutions, thus has not changed the technical situation of the subject matter. At the present time, the commercially available concrete software represent merely codified versions of the simplified methods or numerically integrate the stresses over areas via dividing the given section into layers or fibers and techniques. The integration techniques were disputed among researchers with regard to the numeric efficiency, the time required for convergence, the large amount of information required to characterize the section, and the large number of numerical operations needed to reach an acceptable solution. In addition, article after article has reported a number of limitations such as uniform distribution of reinforcement, identical reinforcing bars, fixed step-by-step iterative procedures, and over design solutions.

The aim of this paper is to institute a closed form formulation for concrete beams under biaxial bending and axial force that meet the following objectives:

1. To calculate the exact strength capacities under bending and axial force.

2. To provide a generic computer tool for practice without procedural limitations.

\section{Formulation:}

The following main assumptions underline the closed form formulation:

1. Plane sections remain plane before and after deformation.

2. The compression stress in the concrete is represented in two independent ways: 
- A rectangular with stress of $0.85 \mathrm{fc}^{\prime}$ and a depth of $\square_{1} \mathrm{C}$.

- A parabola: $\mathrm{f}_{\mathrm{c}}=\mathrm{f}_{\mathrm{c}}^{\prime}\left(1-\left(1-\frac{\mathrm{y}}{\mathrm{c}}\right)^{2}\right)$

in which

$\mathrm{fc}^{\prime}=$ The ultimate compression strength of concrete;

$\mathrm{C}=$ The neutral axis depth as shown in Fig. 1;

$y=$ Cartesian coordinate;

$\beta_{1}=0.85 \quad$ if $\mathrm{f}_{\mathrm{c}}^{\prime} \leq 4 \mathrm{ksi}$

$\beta_{1}=0.05\left(\mathrm{f}_{\mathrm{c}}^{\prime}-4\right) \quad$ if $\mathrm{f}_{\mathrm{c}}^{\prime}>4 \mathrm{ksi}$

The concept of parabolic stress distribution is known in research (Bonet et. al., 2006; De Vivo, L. and Rosati, L., 1987, Liang, 2008).

3. The stress-strain relation for the steel is considered elasto-plastic as follow:

$$
\begin{array}{ll}
\mathrm{f}_{\mathrm{s}}=\varepsilon_{\mathrm{s}} \mathrm{E}_{\mathrm{s}} & \text { if } \varepsilon_{\mathrm{s}}<\varepsilon_{\mathrm{y}} \\
\mathrm{f}_{\mathrm{s}}=\mathrm{f}_{\mathrm{y}} & \text { if } \varepsilon_{\mathrm{s}} \geq \varepsilon_{\mathrm{y}} \\
\text { in which } &
\end{array}
$$$$
f_{s}=\text { The stress of a reinforcing bar; }
$$$$
\square_{s}=\text { The strain of a reinforcing bar; }
$$$$
f_{y}=\text { The yield strength of the reinforcing steel; }
$$$$
\mathrm{E}_{\mathrm{s}}=\text { The modulus of elasticity of steel. }
$$

Assumption no. 1 implies that the strain distribution is linear across the section. Thus, the strain, $\square_{\mathrm{si}}$ of the ith reinforcing bar can be determined using the following geometric formulae:

$\varepsilon_{\mathrm{si}}^{\prime}=\varepsilon_{\mathrm{c}}\left(1-\left(\frac{\mathrm{b}}{2 \mathrm{c}}-\frac{\mathrm{x}_{\mathrm{si}}^{\prime}}{\mathrm{c}}\right) \sin \theta-\frac{\mathrm{c}_{\mathrm{si}}^{\prime}}{\mathrm{c}} \cos \theta\right) \quad$ for barsin the compression area

$\varepsilon_{\mathrm{si}}=\varepsilon_{\mathrm{c}}\left(-1+\left(\frac{\mathrm{b}}{2 \mathrm{c}}-\frac{\mathrm{x}_{\mathrm{si}}}{\mathrm{c}}\right) \sin \theta+\left(\frac{\mathrm{h}}{\mathrm{c}}-\frac{\mathrm{c}_{\mathrm{si}}}{\mathrm{c}}\right) \cos \theta\right) \quad$ for the main tension steel

in which

$x$ and $y=$ The Cartesian coordinates of the ith bar;

$\mathrm{b}$ and $\mathrm{h}=$ The width and depth of the section;

c' = The concrete cove.

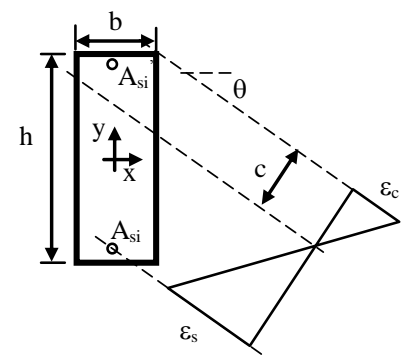

Figure 1: Strain Distribution

Once the strains are determined, the associated stresses can be calculated using assumptions 2 and 3 above, and subsequently directly integrated over the appropriate areas to obtain the resultant forces. 


\section{Rectangle stress block}

$$
\begin{aligned}
\mathrm{N}= & \left(-\mathrm{k}_{2}+\mathrm{k}_{1} \mathrm{c}\right)\left(0.85 \mathrm{f}_{\mathrm{c}}^{\prime}\right)+\varepsilon_{\mathrm{c}} \mathrm{E}_{\mathrm{s}} \sum_{\mathrm{i}=1}^{\mathrm{n}}\left(1-\frac{\frac{\mathrm{b}}{2}-\mathrm{x}_{\mathrm{si}}^{\prime}}{\mathrm{c}} \sin \theta-\frac{\mathrm{c}_{\mathrm{si}}^{\prime}}{\mathrm{c}} \cos \theta\right) \mathrm{A}_{\mathrm{si}}^{\prime} \\
+ & \mathrm{f}_{\mathrm{y}}\left(\sum_{\mathrm{i}=1}^{\mathrm{n}} \mathrm{A}_{\mathrm{si}}^{\prime}-\sum_{\mathrm{i}=1}^{\mathrm{n}} \mathrm{A}_{\mathrm{si}}\right) \\
\mathrm{M}_{\mathrm{x}}= & \varepsilon_{\mathrm{c}} \mathrm{E}_{\mathrm{s}}\left(\sum_{\mathrm{i}=1}^{\mathrm{n}} \mathrm{A}_{\mathrm{si}}^{\prime} \mathrm{y}_{\mathrm{si}}^{\prime}-\frac{\mathrm{b}}{2 \mathrm{c}} \sin \theta \sum_{\mathrm{i}=1}^{\mathrm{n}} \mathrm{A}_{\mathrm{si}}^{\prime} \mathrm{y}_{\mathrm{si}}^{\prime}+\frac{\sin \theta}{\mathrm{c}} \sum_{\mathrm{i}=1}^{\mathrm{n}} \mathrm{A}_{\mathrm{si}}^{\prime} \mathrm{x}_{\mathrm{si}}^{\prime} \mathrm{y}_{\mathrm{si}}^{\prime}\right. \\
& \left.-\frac{\mathrm{c}^{\prime}}{\mathrm{c}} \cos \theta \sum_{i=1}^{n} \mathrm{~A}_{\mathrm{si}}^{\prime} \mathrm{y}_{\mathrm{si}}^{\prime}\right)+\left(0.85 \mathrm{f}_{\mathrm{c}}^{\prime}\right)\left(\frac{\mathrm{b}^{2}}{2} \operatorname{tanq} \theta\left(\frac{\mathrm{h}}{2}-\frac{\mathrm{b} \tan \theta}{3}\right)\right. \\
& +\left(\frac{\mathrm{h}}{2}-\frac{\mathrm{b}}{2} \tan \theta\right)\left(\frac{\mathrm{b}}{\cos \theta}\right)\left(\beta_{1} \mathrm{c}-\mathrm{b} \sin \theta\right) \\
& \left.-\frac{\mathrm{b}}{2 \sin \theta \cos \theta}\left(\beta_{1}^{2} \mathrm{c}^{2}-2 \beta_{1} \mathrm{cb} \sin \theta+\mathrm{b}^{2} \sin { }^{2} \theta\right)\right) \\
& +\mathrm{f}_{\mathrm{y}}\left(\sum_{\mathrm{i}=1}^{\mathrm{n}} \mathrm{A}_{\mathrm{si}}^{\prime} \mathrm{y}_{\mathrm{si}}^{\prime}-\sum_{\mathrm{i}=1}^{\mathrm{n}} \mathrm{A}_{\mathrm{si}} \mathrm{y}_{\mathrm{si}}\right) \\
\mathrm{M}_{\mathrm{y}}= & \varepsilon_{\mathrm{c}} \mathrm{E}_{\mathrm{s}}\left(\sum_{\mathrm{i}=1}^{\mathrm{n}} \mathrm{A}_{\mathrm{si}}^{\prime} \mathrm{x}_{\mathrm{si}}^{\prime}-\frac{\mathrm{b}}{2 \mathrm{c}} \sin \theta \sum_{\mathrm{i}=1}^{\mathrm{n}} \mathrm{A}_{\mathrm{si}}^{\prime} \mathrm{x}_{\mathrm{si}}^{\prime}\right. \\
& \left.-\frac{\mathrm{c}^{\prime}}{\mathrm{c}} \cos \theta \sum_{\mathrm{i}=1}^{\mathrm{n}} \mathrm{A}_{\mathrm{si}}^{\prime} \mathrm{x}_{\mathrm{si}}^{\prime}+\frac{\sin \theta}{\mathrm{c}} \sum_{\mathrm{i}=1}^{\mathrm{n}} \mathrm{A}_{\mathrm{si}}^{\prime} \mathrm{x}_{\mathrm{si}}^{2}\right) \\
& +\frac{1}{12} \mathrm{~b}^{3} \tan \theta\left(0.85 \mathrm{f}_{\mathrm{c}}^{\prime}\right)+\mathrm{f}_{\mathrm{y}}\left(\sum_{\mathrm{i}=1}^{\mathrm{n}} \mathrm{A}_{\mathrm{si}}^{\prime} \mathrm{x}_{\mathrm{si}}^{\prime}+\sum_{\mathrm{i}=1}^{\mathrm{n}} \mathrm{A}_{\mathrm{si}} \mathrm{x}_{\mathrm{si}}\right) \\
&
\end{aligned}
$$

in which

$$
\begin{aligned}
& \mathrm{k}_{1}=\frac{\beta_{1} \mathrm{~b}}{\cos \theta} \\
& \mathrm{k}_{2}=\mathrm{b}^{2}\left(\sin \theta \cos \theta+\tan \theta \sin ^{2} \theta-\frac{1}{2} \tan \theta\right)
\end{aligned}
$$




\section{Parabolic stress distribution}

$$
\begin{aligned}
\mathrm{N}_{\mathrm{c}}= & \frac{\mathrm{bf_{ \textrm {c } } ^ { \prime }}}{3 \cos \theta}\left(\frac{\mathrm{c}_{1}}{\mathrm{c}}\right)^{2}\left(3 \mathrm{c}-\mathrm{c}_{1}\right)+ \\
& \frac{\mathrm{f}_{\mathrm{c}}^{\prime}}{\sin \theta \cos \theta} \frac{\mathrm{c}^{4}-4 \mathrm{c}^{2} \mathrm{c}_{1}^{2}+4 \mathrm{cc}_{1}^{3}-\mathrm{c}_{1}^{4}}{4 \mathrm{c}^{2}}
\end{aligned}
$$

in which

$\mathrm{c}_{1}=\mathrm{c}-\mathrm{b} \cos \theta$

The coordinates of the point at which $\mathrm{N}_{\mathrm{c}}$ acts are found as follow:

$\bar{y}=\frac{A_{u} y_{u}+A_{L} y_{L}}{A_{u}+A_{L}}$ from the neutral axis

$\bar{x}=\frac{A_{u}\left(\frac{b}{2}-\frac{y_{u}}{\tan \theta}\right)}{A_{u}+A_{L}}$ from the y-axis

in which

$$
\begin{aligned}
& \mathrm{A}_{\mathrm{u}}=\frac{\mathrm{c}^{2}}{2 \sin \theta \cos \theta} \\
& \mathrm{A}_{\mathrm{L}}=\frac{\mathrm{b} \mathrm{c}_{1}}{\cos \theta} \\
& \mathrm{y}_{\mathrm{L}}=\frac{\mathrm{c}_{1}}{4 \mathrm{c}} \frac{5 \mathrm{c}+3 \mathrm{~b} \sin \theta}{2 \mathrm{c}+\mathrm{b} \sin \theta} \\
& \mathrm{y}_{\mathrm{u}}=\frac{2}{15 \cos \theta} \frac{2 \mathrm{c}^{5}-15 \mathrm{c}^{3} \mathrm{c}_{1}^{2}+25 \mathrm{c}^{2} \mathrm{c}_{1}^{3}-15 \mathrm{c} \mathrm{c}_{1}^{4}+3 \mathrm{c}_{1}^{5}}{\mathrm{c}^{4}+4 \mathrm{c}^{3} \mathrm{c}_{1}^{3}-4 \mathrm{c}^{2} \mathrm{c}_{1}^{2}-\mathrm{c}_{1}^{4}}
\end{aligned}
$$

The resultant forces must equal to the applied ones. This is written in the following mathematic formulae:

$$
\begin{aligned}
& F_{a}=N \\
& M_{x a}=M_{x} \\
& M_{y a}=M_{y}
\end{aligned}
$$

in which

$\mathrm{F}_{\mathrm{a}}=$ Applied axial force;

$\mathrm{M}_{\mathrm{xa}}=$ Applied bending moment about the $\mathrm{x}$ axis;

$\mathrm{M}_{\mathrm{ya}}=$ Applied bending moment about the $\mathrm{y}$ axis.

By substituting equations 1 to 11 in equation 12, one could see the three transcendental equations to be solved simultaneously. 


\section{Examples}

Five problems are solved to demonstrate the validity and viability of the approach presented in this paper. Table 1 summarizes the input data and the solutions obtained.

Table 1: Numeric Examples

\begin{tabular}{|c|c|c|c|c|c|}
\hline & $\begin{array}{l}\text { Type of } \\
\text { Problem }\end{array}$ & Given & Results & $\begin{array}{l}\text { Published } \\
\text { Solutions }\end{array}$ & Ref. \\
\hline 1 & $\begin{array}{l}\text { Biaxial } \\
\text { Rect. stress }\end{array}$ & $\begin{array}{l}\mathrm{b}=12 \mathrm{in} \\
\mathrm{h}=22 \mathrm{in} \\
\mathrm{f}_{\mathrm{c}}{ }^{\prime}=4 \mathrm{ksi} \\
\mathrm{f}_{\mathrm{y}}=60 \mathrm{ksi} \\
\mathrm{A}_{\mathrm{s}}=\mathrm{A}_{\mathrm{s}}=3 \times 0.79 \mathrm{in}^{2}\end{array}$ & $\begin{array}{l}\theta=30^{\circ} \\
C=10.0 \mathrm{in} \\
N=220 \\
M_{x}=4031 \mathrm{k} . \mathrm{in} \\
M_{y}=370 \mathrm{k} . \mathrm{in}\end{array}$ & $\begin{array}{l}\theta=30^{\circ} \\
C=10 \mathrm{in} \\
N=220 \mathrm{lb} \\
M_{x}=4032 \mathrm{k} . \mathrm{in} \\
M_{y}=370 \mathrm{k} . \mathrm{in}\end{array}$ & Bresler \\
\hline 2 & $\begin{array}{l}\text { Uniaxial } \\
\text { T-Section } \\
\text { Rect. stress }\end{array}$ & $\begin{array}{l}\mathrm{b}_{\text {flange }}=28 \mathrm{in} \\
\mathrm{b}_{\text {web }}=10 \mathrm{in} \\
\mathrm{h}=30 \mathrm{in} \\
\mathrm{f}_{\mathrm{c}}{ }^{\prime}=3 \mathrm{ksi} \\
\mathrm{f}_{\mathrm{y}}=60 \mathrm{ksi} \\
\mathrm{A}_{\mathrm{s}}=0 \\
\mathrm{~A}_{\mathrm{s}}=6 \times 1.27 \mathrm{in}^{2}\end{array}$ & $\begin{array}{l}\theta=0^{\circ} \\
C=8.4 \mathrm{in} \\
N=0 \\
M_{x}=10603 \mathrm{k} \cdot \mathrm{in} \\
M_{y}==0 \mathrm{k} . \mathrm{in}\end{array}$ & $\begin{array}{l}\theta=0^{\circ} \\
C=8.4 \text { in } \\
N=0 \\
M_{x}=10411 \\
\text { K.in } \\
M_{y}=0 \text { k.in }\end{array}$ & Nilson \\
\hline 3 & $\begin{array}{l}\text { Biaxial } \\
\text { Case I } \\
\text { Rect. stress }\end{array}$ & $\begin{array}{l}\mathrm{b}=12 \mathrm{in} \\
\mathrm{h}=24 \mathrm{in} \\
\mathrm{f}_{\mathrm{c}}^{\prime}=3 \mathrm{ksi} \\
\mathrm{f}_{\mathrm{y}}=60 \mathrm{ksi} \\
\mathrm{A}_{\mathrm{s}}=2 \times 0.44 \mathrm{in}^{2} \\
\mathrm{~A}_{\mathrm{s}}=2 \times 1 \mathrm{in}^{2} \\
\mathrm{~F}_{\mathrm{a}}=5 \mathrm{k} \\
\mathrm{M}_{\mathrm{xa}}=2300 \mathrm{k} \cdot \mathrm{in} \\
\mathrm{M}_{\mathrm{ya}}=275 \mathrm{k} \cdot \mathrm{in}\end{array}$ & $\begin{array}{l}\theta=30.2^{\circ} \\
c=7 \mathrm{in} \\
\text { Axial Force }=5 \mathrm{k} \\
M_{x}=2348 \mathrm{k} . \text { in } \\
M_{y}=281 \mathrm{k} . \text { in }\end{array}$ & & \\
\hline 4 & $\begin{array}{l}\text { Biaxial } \\
\text { T-Section } \\
\text { Rect. stress }\end{array}$ & $\begin{array}{l}b_{\text {flange }}=28 \text { in } \\
b_{\text {web }}=10 \mathrm{in} \\
h=30 \mathrm{in} \\
f_{c}=3 \mathrm{ksi} \\
f_{y}=60 \mathrm{ksi} \\
A_{s}=3 \times 1.27 \mathrm{in}^{2} \\
A_{s}=3 \times 2.54 \text { in }^{2} \\
F_{a}=50 \mathrm{k} \text { (compression) }\end{array}$ & $\begin{array}{l}\theta=40.2^{\circ} \\
C=7.6 \mathrm{in} \\
N=50 \mathrm{k} \\
M_{x}=11450 \mathrm{k} . \mathrm{in} \\
M_{y}=349 \mathrm{k} . \mathrm{in}\end{array}$ & & \\
\hline 5 & $\begin{array}{l}\text { Biaxial } \\
\text { T-Section } \\
\text { Rect. stress }\end{array}$ & $\begin{array}{l}\mathrm{b}_{\text {flange }}=28 \mathrm{in} \\
\mathrm{b}_{\text {web }}=10 \mathrm{in} \\
\mathrm{h}=30 \mathrm{in} \\
\mathrm{f}_{\mathrm{c}}^{\prime}=3 \mathrm{ksi} \\
\mathrm{f}_{\mathrm{y}}=60 \mathrm{ksi} \\
\mathrm{A}_{\mathrm{s}}=3 \times 1.27 \mathrm{in}^{2} \\
\mathrm{~A}_{\mathrm{s}}=3 \times 2.54 \mathrm{in}^{2} \\
\mathrm{~F}_{\mathrm{a}}=50 \mathrm{k} \text { (tension) }\end{array}$ & $\begin{array}{l}\theta=25.3^{\circ} \\
C=5.0 \mathrm{in} \\
N=50 \mathrm{k} \\
M_{x}=10263 \mathrm{k} . \mathrm{in} \\
M_{y}=270 \mathrm{k} . \mathrm{in}\end{array}$ & & \\
\hline
\end{tabular}




\section{Conclusions:}

Since 1844, several noteworthy articles on biaxial bending of concrete column sections were published and contributed significantly to the understanding of this subject. Nonetheless, the literature neither included closed form solutions for the relevant beam sections nor demonstrated those findings on beam sections. This paper fills this gap.

In this paper a new exact solution is obtained for reinforced concrete beam sections under biaxial bending and axial force. Because of the mathematic nature inherited in the transcendental closed form formulae, this novel approach was enhance by complete automation. For that purpose, the paper introduced the use of the concept of modular procedure as a generic computational means. In this way, many of the shortcomings of the documented procedures were resolved, and the designer becomes the decision maker and in control of the computer processors. The soundness of the approach was demonstrated by solving a wide range of diverse problems some of which were solved manually in the literature by notable scholars in the field.

\section{References:}

[1] Bonet a, J. L., et. al., "Comparative study of analytical and numerical algorithms for designing reinforced concrete sections under biaxial bending," Computers and Structures, vol. 84, 2006.

[2] Bresler, B., "Reinforced Concrete Engineering," John Wiley, 1974.

[3] De Vivo, L. and Rosati, L., "Ultimate strength analysis of reinforced concrete sections subject to axial force and biaxial bending," Computing Methods in Applied Mechanic Engineering, vol. 166, 1998.

[4] Liang, Q. Q., "Nonlinear analysis of short concrete-filled steel tubular beam-columns under axial load and biaxial bending," Journal of Constructional Steel Research, vol. 64, 2008.

[5] Mathworks, Inc., "Matlab", http://www.mathworks.com/

[6] Nilson, A., et. al., "Design of Concrete Structures," McGraw-Hill Higher Education, 1972

[7] Pallarés, L., et. al., "The influence of the weak axis on the behavior of high strength RC slender columns subjected to biaxial bending," Engineering Structures, vol. 31, 2009.

[8] Park, R. and Paulay, T., "Reinforced concrete structures," John Wiley, 1975

[9] Park, R., "Rectangular beams subjected to biaxial bending," Concrete, Vol. 1, No. 12, Dec, 1967

[10] PTC, Inc., "Mathcad", http://www.ptc.com/company/index.htm.

[11] Wikipedia, Modular programming, http://en.wikipedia.org/wiki/Modular_programming

[12] Wolframe Research Inc., "Mathematica", http://www.wolfram.com/products/mathematica/index.html. 